\title{
PERFIL DO AGRESSOR E FATORES ASSOCIADOS À VIOLÊNCIA CONTRA MULHERES*
}

\author{
Marilena Silva de Vasconcelos ${ }^{1}$, Viviane Rolim de Holanda ${ }^{2}$, Thaíse Torres de Albuquerque ${ }^{3}$
}

\begin{abstract}
RESUMO: Objetivou-se analisar o perfil do agressor e os fatores associados à violência contra as mulheres. Tratase de estudo transversal e documental, realizado na Secretaria da Mulher, do município Vitória de Santo Antão, estado de Pernambuco. A amostra foi censitária e composta por 512 fichas, referente a junho de 2008 a dezembro de 2012. Para análise dos dados, aplicou-se o Teste Qui-quadrado e nível de significância de 5\%. Verificou-se que os agressores eram homens jovens (36\%), viviam em união estável com as vítimas $(37,8 \%, p<0,001)$, sendo estes o marido ou companheiro conjugal $(53,4 \%, \mathrm{p}<0,001)$. A violência física $(65 \%)$ e psicológica $(60,4 \%)$ foram as mais frequentes. Diante dos resultados, é imperativo elaborar estratégias de enfrentamento, baseadas no perfil do agressor, que possam auxiliar no combate às desigualdades de gênero, além de desenvolver medidas interventivas que colaborem com a prevenção, promoção da saúde e assistência às mulheres em situação de violência.
\end{abstract}

DESCRITORES: Enfermagem; Enfermagem em saúde comunitária; Violência de gênero; Fatores socioeconômicos.

\section{PROFILE OF THE AGGRESSOR AND FACTORS ASSOCIATED WITH VIOLENCE AGAINST WOMEN}

ABSTRACT: The objective was to analyze the aggressor's profile and the factors associated with violence against women. A crosssectional and documentary study was undertaken at the Women's Police Station in the city of Vitória de Santo Antão, state of Pernambuco, Brazil. A census sample of 512 forms was used, covering the period from June 2008 till December 2012. To analyze the data, the chi-square test was applied and significance was set at $5 \%$. It was verified that the aggressors were young men (36\%), who lived in a fixed relationship with the victims $(37.8 \%, \mathrm{p}<0.001)$, being the husband or partner $(53.4 \%, \mathrm{p}<0.001)$. Physical $(65 \%)$ and psychological violence $(60.4 \%)$ were the most frequent. In view of the results, it is fundamental to elaborate coping strategies based on the aggressor's profile, which can help in the fight against gender inequalities, besides developing intervention measures that cooperate with prevention, health promotion and assistance to the women in situations of violence.

DESCRIPTORS: Nursing; Community health Nursing; Gender violence; Socioeconomic factors.

\section{PERFIL DEL AGRESOR Y FACTORES ASOCIADOS A LA VIOLENCIA CONTRA MUJERES}

RESUMEN: Fue objetivo del estudio analizar el perfil del agresor y los factores asociados a la violencia contra mujeres. Es un estudio transversal y documental, realizado en la Secretaría de la Mujer, del municipio Vitória de Santo Antão, estado de Pernambuco. La muestra fue censitaria y compuesta por 512 fichas, ubicada entre junio de 2008 y diciembre de 2012. Para análisis de los datos, fue aplicado el Test Chi-cuadrado y nivel de significancia de $5 \%$. Se ha verificado que los agresores eran hombres jóvenes (36\%), vivían en unión estable de hecho con las víctimas $(37,8 \%$, $p<0,001)$, siendo estos el marido o compañero conyugal $(53,4 \%$, $p<0,001)$. La violencia física $(65 \%)$ y psicológica $(60,4 \%)$ fueron las más frecuentes. Delante de los resultados, es imperativo elaborar estrategias de afrontamiento, basadas en el perfil del agresor, las cuales puedan auxiliar en la lucha contra desigualdades de género, además de desarrollar medidas de intervención que ayuden con la prevención, promoción de las alud y asistencia a las mujeres en situación de violencia.

DESCRIPTORES: Enfermería; Enfermería en salud comunitaria; Violencia de género; Factores socioeconómicos.

*Artigo extraído de Trabalho de Conclusão de Curso intitulado: "Análise do perfil do agressor e dos fatores associados à violência contra as mulheres". Universidade Federal de Pernambuco, 2013.

${ }^{1}$ Enfermeira. Pós-Graduanda em Saúde Pública. Enfermeira do Centro de Atenção Psicossocial II- Bezerros. Universidade Federal de Pernambuco. Vitória de Santo Antão-PE-Brasil.

${ }^{2}$ Enfermeira. Doutora em Enfermagem. Docente do Departamento de Enfermagem da Universidade Federal de Pernambuco. Vitória de Santo Antão-PE-Brasil.

${ }^{3}$ Enfermeira. Mestre em Saúde Humana e Meio Ambiente. Docente do Departamento de Enfermagem do Centro Universitário Vale do Ipojuca. Caruaru-PE-Brasil.

Universidade Federal de Pernambuco

R. Nove de Janeiro, 216 - 55660-000 - Bezerros, PE, Brasil

E-mail: marilenavasconcelos.enf@gmail.com 


\section{- INTRODUÇÃO}

A desigualdade de gênero aparece como uma das grandes incongruências da história da civilização e insere a mulher, muitas vezes, em posição social de subordinação e dependência. Essa desigualdade se traduz em violência, que por sua vez resulta em assimetria de poder baseada nas relações de dominação e força ${ }^{(1)}$.

A violência de gênero apresenta-se como problema social que influencia diretamente no viver, adoecer e morrer das mulheres ${ }^{(1)}$. Está intrínseco que há vários fatores que se inter-relacionam no seu vínculo com a origem da família patriarcal, que envolve gênero, educação e sociedade ${ }^{(2)}$.

Por conseguinte, reconhece-se como violência contra as mulheres qualquer ação ou omissão fundamentada no gênero que cause morte, lesão, sofrimento físico, sexual ou psicológico e dano moral ou patrimonial à mulher ${ }^{(3-5)}$.

Um estudo que foi realizado no município de João Pessoa, estado da Paraíba, na Delegacia Especializada de Atendimento à Mulher (DEAM), evidenciou situações que potencializam os efeitos da violência contra as mulheres e que determinam a sua invisibilidade. A primeira refere-se ao fato da mulher não denunciar o ato violento com demonstração de queixas vagas e imediatas aos danos físicos; a recorrência de assistência fragmentada fundamentada na herança das programações de saúde. A segunda, à influência de identidades de gênero no decorrer das vidas das mulheres, impregnadas de estereótipos que resultam em submissão e obediência ${ }^{(1)}$.

Observa-se em resultado de pesquisa realizada em duas Delegacias da Mulher do município de São Paulo o ciclo vicioso da violência, o qual apontou o principal agressor como sendo o marido ou companheiro com quem a mulher manteve relação afetiva. Apesar das mulheres denunciarem o ocorrido na delegacia, um boa parcela das mulheres não continuavam com o processo ${ }^{(4)}$.

Pesquisa realizada em dezenove serviços de saúde no estado de São Paulo revelou que a violência doméstica afeta a saúde das mulheres representando obstáculo na procura do planejamento familiar, nas ações de proteção das doenças sexualmente transmissíveis (DST/HIV) e dos cuidados obstétricos ${ }^{(6)}$.

Em virtude da relevância dessa questão, destacam-se, na conjuntura das políticas sociais, a Constituição Federal de 1988 e a Lei no 11.340 de agosto de 2006, conhecida como Lei Maria da Penha, como marcos no avanço histórico da igualdade entre homens e mulheres ${ }^{(3)}$.

A Lei Maria da Penha tem foco na proteção das mulheres brasileiras contra a violência doméstica e familiar. É importante ressaltar que esta lei, além de contribuir com a segurança e proteção das mulheres para uma vida sem violência, é essencial para promover o debate com as organizações formais e informais da sociedade sobre a temática da violência de gênero ${ }^{(7-8)}$. $\mathrm{Em}$ acréscimo, destaca-se $\mathrm{o}$ papel dos profissionais de saúde, em especial o enfermeiro que atua na atenção primária de saúde, no enfrentamento das situações de violência contra as mulheres. Estes devem contemplar as iniquidades sociais e valorizar o contexto socioeconômico dos usuários no sentido de identificar situações que comprometam a condição de saúde da população ${ }^{(9)}$.

Há um número significativo de mulheres cotidianamente violentadas, o que as tornam vulneráveis ao adoecimento, seja orgânico ou psíquico. Nessa direção, considera-se a atenção primária de saúde como lócus privilegiado para identificar, assistir e referir às mulheres vitimadas pela violência. No entanto, muitas mulheres procuram os serviços de saúde por causa de problemas advindos da violência sofrida e não para relatar o caso. Portanto, ao atendê-las, é necessário que o profissional da saúde acolha estas mulheres, investigue o motivo da consulta com uma escuta sensível e sem julgamentos, além de buscar notificar os casos identificados ${ }^{(2)}$.

A violência contra as mulheres é problema atual embora seja um tema pouco abordado pelos profissionais de saúde. No Brasil, ainda são escassos estudos que discutam o perfil do agressor e os fatores associados à violência, principalmente nas regiões do Norte e Nordeste, mesmo reconhecendo que este fenômeno viola os direitos humanos das mulheres, prejudicando-as em sua vida e saúde. Portanto, é relevante ampliar as investigações frente às lacunas e achados epidemiológicos locais em todo o território nacional, visto que a dinâmica violenta é compreendida de maneira multifatorial e 
diversificada, atingindo em grande proporções todas as regiões do nosso país ${ }^{(10)}$.

Logo, objetivou-se analisar o perfil socioeconômico do agressor e os fatores associados à violência contra as mulheres em um município da Zona da Mata Pernambucana.

\section{- MÉTODO}

Trata-se de estudo transversal e documental, realizado na Secretaria da Mulher do município Vitória de Santo Antão, localizado na Zona da Mata Pernambucana, Região Nordeste do Brasil. A Zona da Mata Pernambucana é constituída por 43 municípios, dentre eles, o que optamos por espaço de pesquisa destaca-se pelos altos índices de violência e de homicídio feminino ${ }^{(11)}$. Percebeu-se, portanto, a necessidade de realizar estudo sobre o perfil do agressor, uma vez que o município com 134.871 habitantes não dispunha de dados epidemiológicos anteriores sobre este tema.

A Secretaria da Mulher desse município é destinada à prevenção e ao acompanhamento das mulheres em situação de violência. Esta instituição atende mulheres vítimas ou em situação de risco de violência e executa ações de prevenção e combate à violação dos direitos humanos no âmbito municipal, além de contribuir com atividades para melhoria das condições de vida das mulheres.

Os dados foram obtidos consultando todas as fichas de atendimento da Secretaria da Mulher, nas quais se realizaram anotações de casos de violência durante o período de junho de 2008 a dezembro de 2012, tratando-se, portanto de uma amostra censitária.

Para tanto, foram escolhidas as seguintes variáveis do agressor: faixa etária, estado civil, renda, tempo de relacionamento com a vítima, relação entre os envolvidos, motivos que a vítima atribuiu à violência sofrida, frequência dos atos violentos, uso de drogas pelo agressor, tipo da droga consumida e tipo de violência.

Para o processo analítico dos dados construiu-se uma planilha específica que foi exportada, posteriormente, para um software de análise estatística. No procedimento descritivo dos dados, calcularam-se as taxas de prevalência, as frequências percentuais e as distribuições de frequência das variáveis analisadas. No procedimento inferencial aplicou-se o teste qui-quadrado para comparação de proporção das variáveis e associação existente entre variáveis qualitativas. Nos testes realizados, o nível de significância adotado foi de $5 \%(p<0,05)$ e o intervalo de confiança foi de $95 \%$ (IC 95\%).

O estudo seguiu os princípios éticos da pes $\neg q u i s a$ com aprovação do Comitê de Ética em Pesquisa da Universidade Federal de Pernambuco (protocolo no 495/11).

\section{RESULTADOS}

Foram analisados 512 casos de violência contra a mulher. Verifica-se na Tabela 1 que 90 homens $(36 \%, p<0,001)$ envolvidos nos casos de violência de gênero possuíam idade entre 19 a 30 anos; 62 $(37,8 \%, p<0,001)$ viviam em união estável com as vítimas e $96(93,2 \%, p<0,001)$ possuíam renda própria.

Quanto à relação entre os envolvidos, observa-se que em 198 casos $(53,4 \%, p<0,001)$ os agressores eram companheiros conjugais/maridos das vítimas, com prevalência de tempo de $37,2 \%(p<0,001)$ de relacionamento afetivo de mais de 10 anos. Dos casos analisados, 53 mulheres $(38,4 \%, p<0,001)$ relacionaram a violência sofrida ao uso abusivo do álcool pelo parceiro no momento da agressão. Com relação à ocorrência dos atos violentos, 76 mulheres $(67,9 \%, p<0,001)$ declararam sofrer violência frequentemente. Em todos os fatores avaliados, o teste de comparação de proporção foi significativo.

Observou-se que a violência física (333 casos, 65\%) e a violência psicológica (309 casos, 60,4\%) foram as mais frequentes na população do estudo. Em seguida, decorreram a violência moral (87 casos, 17\%), violência patrimonial (53 casos, 10,4\%) e violência sexual (31 casos, 6,1\%).

A Tabela 2 apresenta a prevalência da ocorrência da violência segundo o tipo e os fatores associados ao perfil do agressor. Verifica-se que a violência física $(p<0,001)$ é mais praticada por homens com 
Tabela 1- Variáveis relacionadas ao perfil do agressor da mulher em situação de violência. Vitória de Santo Antão, PE, Brasil, 2013

\begin{tabular}{|c|c|c|c|}
\hline Fator avaliado & $\mathbf{n}$ & $\%$ & p-valor ${ }^{1}$ \\
\hline \multicolumn{4}{|l|}{ Idade (anos) $(\mathrm{n}=250)^{*}$} \\
\hline$<18$ & 5 & 2 & \multirow[t]{6}{*}{$<0,001$} \\
\hline 19 a 30 & 90 & 36 & \\
\hline 31 a 40 & 84 & 33,6 & \\
\hline 41 a 50 & 38 & 15,2 & \\
\hline 51 a 60 & 24 & 9,6 & \\
\hline$>60$ & 9 & 3,6 & \\
\hline \multicolumn{4}{|l|}{ Estado civil $(n=164)^{*}$} \\
\hline Casado & 49 & 29,9 & \multirow[t]{4}{*}{$<0,001$} \\
\hline Divorciado/Separado & 14 & 8,5 & \\
\hline Solteiro & 39 & 23,8 & \\
\hline União estável & 62 & 37,8 & \\
\hline \multicolumn{4}{|l|}{ Renda própria $(n=103)^{*}$} \\
\hline Sim & 96 & 93,2 & \multirow[t]{2}{*}{$<0,001$} \\
\hline Não & 7 & 6,8 & \\
\hline \multicolumn{4}{|c|}{ Relação com o agressor $(n=371)^{*}$} \\
\hline Parente de grau $1^{\circ}$ e $2^{\circ}$ & 47 & 12,7 & \multirow{4}{*}{$<0,001$} \\
\hline Marido/companheiro & 198 & 53,4 & \\
\hline Ex-companheiro & 115 & 31 & \\
\hline Conhecido & 11 & 2,9 & \\
\hline \multicolumn{4}{|c|}{ Tempo de relacionamento (anos) $(n=145) *$} \\
\hline $1 \mathrm{a} 4$ & 51 & 35,2 & \multirow[t]{4}{*}{$<0,001$} \\
\hline 5 a 7 & 24 & 16,6 & \\
\hline 8 a 10 & 16 & 11 & \\
\hline 10 ou mais & 54 & 37,2 & \\
\hline \multicolumn{4}{|c|}{ Motivos atribuídos a violência $(n=138) *$} \\
\hline Uso abusivo do álcool & 53 & 38,4 & \multirow[t]{4}{*}{$<0,001$} \\
\hline Ciúmes & 43 & 31,2 & \\
\hline Temperamento agressivo & 31 & 22,5 & \\
\hline Outros & 11 & 7,9 & \\
\hline \multicolumn{4}{|c|}{ Frequência dos atos violentos $(n=112)^{*}$} \\
\hline Esporádica & 16 & 14,2 & \multirow[t]{3}{*}{$<0,001$} \\
\hline Frequente & 76 & 67,9 & \\
\hline Rara & 20 & 17,9 & \\
\hline \multicolumn{4}{|l|}{ Uso de drogas $(n=145)^{*}$} \\
\hline Sim & 125 & 86,2 & \multirow[t]{2}{*}{$<0,001$} \\
\hline Não & 20 & 13,8 & \\
\hline \multicolumn{4}{|l|}{ Tipo de droga $(n=117)^{*}$} \\
\hline Álcool & 103 & 88 & \multirow[t]{5}{*}{$<0,001$} \\
\hline Maconha & 4 & 3,4 & \\
\hline Medicamentos & 1 & 0,9 & \\
\hline Tabaco & 2 & 1,7 & \\
\hline Outra & 7 & 6 & \\
\hline
\end{tabular}


idade entre 19 e 30 anos.

Em relação ao estado civil, os homens que viviam em união estável foram os mais denunciados sobre o crime de violência física $(p<0,001)$, psicológica $(p<0,001)$ e patrimonial $(p=0,043)$. Quanto à situação de renda, os homens que possuíam renda própria apresentaram maior número de notificação na prática de violência física $(p<0,001)$, sexual $(p<0,001)$ e psicológica $(p<0,001)$ enquanto aqueles que

Tabela 2 - Prevalência da ocorrência da violência segundo tipo e fatores associados ao agressor. Vitória de Santo Antão, PE, Brasil, 2013

\begin{tabular}{|c|c|c|c|c|c|}
\hline \multirow[t]{2}{*}{ Fator avaliado } & \multicolumn{5}{|c|}{ Tipo de violência } \\
\hline & Física & Sexual & Psicológica & Moral & Patrimonial \\
\hline \multicolumn{6}{|l|}{ Idade (anos) } \\
\hline$<18$ & $2(40)$ & $0(0)$ & $3(60)$ & $0(0)$ & $1(20)$ \\
\hline 19 a 30 & $68(75,6)$ & $7(7,8)$ & $51(56,7)$ & $12(13,3)$ & $9(10)$ \\
\hline 31 a 40 & $57(67,9)$ & $9(10,7)$ & $66(78,6)$ & $14(16,7)$ & $13(15,5)$ \\
\hline 41 a 50 & $26(68,4)$ & $3(7,9)$ & $28(73,7)$ & $7(18,4)$ & $6(15,8)$ \\
\hline 51 a 60 & $18(75)$ & $3(12,5)$ & $20(83,3)$ & $8(33,3)$ & $2(8,3)$ \\
\hline$>60$ & $4(44,4)$ & $1(11,1)$ & $6(66,7)$ & $2(22,2)$ & $1(11,1)$ \\
\hline $\mathrm{p}$-valor ${ }^{1}$ & $<0,001$ & 0,052 & $<0,001$ & 0,038 & $<0,001$ \\
\hline \multicolumn{6}{|l|}{ Estado civil } \\
\hline Casado & $30(61,2)$ & $7(14,3)$ & $34(69,4)$ & $11(22,4)$ & $4(8,2)$ \\
\hline Divorciado/Separado & $6(42,9)$ & $1(7,1)$ & $10(71,4)$ & $4(28,6)$ & $2(14,3)$ \\
\hline Solteiro & $29(74,4)$ & $5(12,8)$ & $30(76,9)$ & $4(10,3)$ & $3(7,7)$ \\
\hline União estável & $47(75,8)$ & $5(8,1)$ & $48(77,4)$ & $10(16,1)$ & $10(16,1)$ \\
\hline$p$-valor ${ }^{1}$ & $<0,001$ & 0,238 & $<0,001$ & 0,117 & 0,043 \\
\hline \multicolumn{6}{|l|}{ Renda própria } \\
\hline Sim & $67(69,8)$ & $19(19,8)$ & $84(87,5)$ & $12(12,5)$ & $10(10,4)$ \\
\hline Não & $4(57,1)$ & $0(0)$ & $6(85,7)$ & $1(14,3)$ & $1(14,3)$ \\
\hline$p$-valor ${ }^{1}$ & $<0,001$ & $<0,001$ & $<0,001$ & 0,002 & 0,007 \\
\hline \multicolumn{6}{|l|}{ Relação com o agressor } \\
\hline Parente de grau $1^{\circ}$ e $2^{\circ}$ & $31(66)$ & $6(12,8)$ & $22(46,8)$ & $9(19,1)$ & $5(10,6)$ \\
\hline Marido/companheiro & $143(72,2)$ & $13(6,6)$ & $124(62,6)$ & $33(16,7)$ & $21(10,6)$ \\
\hline Ex-companheiro & $64(55,7)$ & $7(6,1)$ & $90(78,3)$ & $18(15,7)$ & $17(14,8)$ \\
\hline Conhecido & $7(63,6)$ & $0(0)$ & $8(72,7)$ & $2(18,2)$ & $1(9,1)$ \\
\hline p-valor ${ }^{1}$ & $<0,001$ & 0,191 & $<0,001$ & $<0,001$ & $<0,001$ \\
\hline \multicolumn{6}{|c|}{ Tempo de relacionamento (anos) } \\
\hline $1 \mathrm{a} 4$ & $37(72,5)$ & $1(2)$ & $34(66,7)$ & $4(7,8)$ & $8(15,7)$ \\
\hline 5 a 7 & $20(83,3)$ & $1(4,2)$ & $17(70,8)$ & $5(20,8)$ & $1(4,2)$ \\
\hline 8 a 10 anos & $12(75)$ & $4(25)$ & $11(68,8)$ & $3(18,8)$ & $1(6,3)$ \\
\hline 10 ou mais & $35(64,8)$ & $7(13)$ & $46(85,2)$ & $13(24,1)$ & $8(14,8)$ \\
\hline $\mathrm{p}$-valor ${ }^{1}$ & 0,001 & 0,055 & $<0,001$ & 0,018 & 0,012 \\
\hline \multicolumn{6}{|l|}{ Motivos atribuídos à violência } \\
\hline Uso abusivo de álcool & $39(73,6)$ & $5(9,4)$ & $41(77,4)$ & $10(18,9)$ & $4(7,5)$ \\
\hline Ciúmes & $30(69,8)$ & $3(7)$ & $31(72,1)$ & $10(23,3)$ & $5(11,6)$ \\
\hline Temperamento agressivo & $28(90,3)$ & $9(29)$ & $28(90,3)$ & $3(9,7)$ & $1(3,2)$ \\
\hline Outros & $7(63,6)$ & $2(18,2)$ & $7(63,6)$ & $0(0)$ & $1(9,1)$ \\
\hline $\mathrm{p}$-valor ${ }^{1}$ & $<0,001$ & 0,109 & $<0,001$ & 0,119 & 0,2 \\
\hline
\end{tabular}

${ }^{1} \mathrm{p}$-valor do teste Qui-quadrado 
não possuíam renda própria mostraram maior prevalência na violência moral $(p=0,002)$ e patrimonial $(p=0,007)$.

Acerca da relação da vítima com o agressor, o marido/companheiro apresentou maior prevalência de registros de violência física $(p<0,001)$. A violência psicológica $(p<0,001)$ e patrimonial $(p<0,001)$ foi praticada com maior frequência entre ex-companheiros conjugais. A violência moral $(p<0,001)$ destacou-se entre agressores com algum grau de parentesco da vítima. O tempo de relacionamento foi proporcional ao maior número de eventos de atos violentos. Homens com 10 ou mais anos de relacionamento apresentaram maior prevalência de violência psicológica $(p<0,001)$ e moral $(p=0,018)$. Dentre os motivos declarados pelas mulheres para a prática da violência, o temperamento agressivo e o uso abusivo de álcool foram prevalentes nos casos de violência física $(p<0,001)$ e psicológica $(p<0,001)$.

\section{DISCUSSÃO}

Violência de gênero, violência conjugal e violência doméstica são alguns termos utilizados para designar um problema social, que na prática são utilizados na análise da violência contra as mulheres e nas relações afetivas, denominada internacionalmente como violência por parceiro íntimo. A ausência de consenso entre esses termos dificulta a demarcação de espaços, bem como a compreensão das causas, efeitos e modalidades da violência, o que é agravado pela falta de dados fidedignos que compreendam melhor os episódios desse problema ${ }^{(12)}$.

Os resultados obtidos sobre a ocorrência da violência contra as mulheres perpetrada por parceiro íntimo assemelham-se a outras pesquisas sobre a temática ${ }^{(2,13-14)}$, as quais mostraram que os companheiros conjugais são os principais denunciados, seguidos por ex-companheiros. Entretanto, nem sempre essa informação é evidenciada, uma vez que muitas mulheres optam por silenciar tal eventualidade.

Pesquisa ${ }^{(13)}$ realizada em Ribeirão Preto, estado de São Paulo, caracterizou o perfil do agressor com faixa etária acima de 35 anos, raça branca, com ensino fundamental completo e trabalho remunerado. Em outra investigação, realizado em um município da região central do estado do Paraná, os agressores eram casados, com baixa escolaridade e trabalho remunerado, que sob efeito de álcool, praticavam violência $^{(15)}$. Estudo realizado na região norte do México apresentou o agressor como sendo adulto jovem, com média de idade de 33 anos, moreno claro, estatura mediana, com atividade laboral na área de segurança, seguida de desempregados ${ }^{(16)}$. Os dados destas pesquisas mostram alguns contrastes parciais com os resultados apresentados nesta pesquisa, na qual o agressor era adulto jovem, na faixa etária entre 19 a 30 anos e com renda própria.

A violência de gênero acontece por meio de um relacionamento afetivo que envolve cônjuges, companheiros atuais ou anteriores. Pode se manifestar em violência física, violência sexual, ameaças e abuso emocional. Na maioria das vezes, inicia com abuso emocional e avança para ofensiva física ou sexual. No entanto, os diversos tipos de violência podem ocorrer simultaneamente ao longo da vida da mulher ${ }^{(17-18)}$.

Ocorre com frequência o sentimento de medo, o que impossibilita a mulher de buscar ajuda e explanar a situação vivenciada. Este tipo de comportamento encoberta o abuso e diminui a gravidade do evento violento por temor/medo, pela ausência de informação e pela falta de consciência sobre o que constitui a agressão; além disso, é recorrente a esperança de que o companheiro não volte a cometer tal evento agressivo ${ }^{(13)}$.

Os resultados encontrados sobre a relação da vítima com o agressor foram equivalentes a outras pesquisas. De acordo com a Central de Apoio Multidisciplinar de Serra, estado do Espírito Santo, as mulheres possuem maior expectativa de serem espancadas pelo companheiro. Somando-se a este evento, encontra-se a vivência de diferentes tipos de violência, que na maioria das vezes, levam as vítimas a receber cuidados de saúde ${ }^{(19)}$.

Um estudo realizado no Irã revelou que o empoderamento das mulheres, por meio da educação e da oportunidade de se ter uma renda estável, pode ajudar a reduzir drasticamente a violência doméstica. Acresce-se aqui o incentivo dos homens em permitir a participação ativa das mulheres nos espaços de 
decisão e a promoção da consciência pública sobre os direitos humano ${ }^{(20)}$.

Estudo mostrou prevalência de 37,9\% de violência física, perpetrada por parceiro íntimo, acometida alguma vez na vida das mulheres residentes da cidade de São Paulo e de 35,2\% nas moradoras da Zona da Mata Pernambucana ${ }^{(21)}$. Já em uma pesquisa realizada com mulheres iranianas, observouse prevalência de $38,7 \%$ de exposição à violência física ao longo de suas vidas. Apontou-se ainda que moradores de áreas urbanas associada com baixa escolaridade, desemprego e menor nível socioeconômico possuíam maior expectativa de sofrer violência física ${ }^{(20)}$.

Segundo o Ministério da Saúde, em um estudo realizado com oito países, o qual inclui o Brasil em dois estados (São Paulo e Pernambuco), observou-se que a morbidez gerada pela violência doméstica e sexual afeta em especial mulheres entre 15-49 anos. No estado de Pernambuco, 34\% da população feminina referiram ter sofrido violência física e/ou sexual pelo parceiro íntimo, seguidos de problemas de saúde como falta de concentração, tonturas, dores, tentativas suicidas, consumo recorrente do álcool, relacionando a violência como tema de saúde física e mental ${ }^{(22)}$.

Com relação à prevalência do tipo de violência sofrida, a agressão física foi a mais praticada contra as mulheres desse estudo, seguida da violência psicológica. Igualmente, análise ${ }^{(23)}$ apontou frequente número de ocorrência de violência física contra a mulher. Outros estudos realizados em unidades de saúde do município de João Pessoa, estado da Paraíba e em hospitais e distritos sanitários de Andaluzia, na Espanha, apresentaram a violência psicológica como prevalente entre os casos investigados ${ }^{(2,24)}$.

A violência física perpetrada por homens na faixa etária entre 19 e 30 anos pode estar associada à condição cultural do gênero agregada à imaturidade de resolução de problemas afetivos dessa classe adulta jovem ${ }^{(23)}$. No entanto, a frequente violência física revela a brutalidade das ações do agressor e envolve desde um puxão de cabelo a casos mais sérios como facadas e fraturas ósseas, o que possibilita o questionamento sobre possíveis ensaios de assassinato pelos quais as vítimas possam ter passado e não ter revelado no momento da coleta de informações ${ }^{(25)}$.

Pesquisa ${ }^{(14)}$ revelou que mais de três quartos das mulheres já foram vítimas de algum tipo de violência na vida, sendo a violência física a mais referida pelo menos uma vez na vida, corroborando com os achados desse estudo.

A violência psicológica denuncia a invisibilidade das agressões cometidas contra as mulheres, uma vez que este tipo de abuso não mostra características físicas da vítima. Nesse sentido, torna complexa sua identificação nas unidades de atendimento pelos profissionais de saúde, ao passo que confirma a carência de qualificação destes prestadores durante a realização de consultas que busquem sinais de violência no atendimento das vítimas ${ }^{(25)}$.

Os episódios de violência tornam-se mais frequentes com aumento do tempo de união entre o casal $^{(21)}$, apoiando os resultados encontrados neste estudo. Pesquisa revelou que a maior parte das mulheres violentadas já registraram entre dois a quatro boletins de ocorrência por abuso contra seus parceiros, fundamentando o ciclo violento como longo e intenso ${ }^{(23)}$.

Os resultados apresentados revelaram o uso abusivo do álcool, seguido pelo ciúme, como principais elementos relatados pelas mulheres para os atos violentos sofridos pelos companheiros. Corroborando com estes resultados, estudo realizado no Instituto de Medicina legal da Catalunha na Espanha, apontou que o álcool e o ciúme estiveram presentes em $39 \%$ e $29 \%$ dos casos, respectivamente ${ }^{(26)}$. Também, uma análise ${ }^{(23)}$ realizada sobre os fatores desencadeantes das agressões contra as mulheres apontou o ciúme e a contrariedade do homem como principais motivos da violência, os quais diferem parcialmente desse estudo. Concordante com outros estudos ${ }^{(7,27-29)}$ o consumo do álcool mostrou-se como fator relacionado às agressões contra as mulheres. É inegável que o uso excessivo do álcool determina sérios problemas sociais como barreiras interpessoais e familiares, violência e criminalidade. Nas unidades básicas de saúde, os profissionais podem aplicar, rotineiramente, instrumentos de detecção precoce do uso do álcool e auxiliar em intervenções capazes de promover mudanças de comportamentos e de estilos de vida das pessoas ${ }^{(30)}$.

A predominância de homens alcoolizados durante os episódios de violência tem sido mais presente do que em mulheres. As distinções de gênero no uso do álcool podem estar relacionadas diretamente ao consumo dessa droga lícita, comumente mais altas entre os homens ${ }^{(27)}$. Este resultado reflete, por 
vezes, na relação do casal, desencadeando as agressões em virtude do homem não aceitar que a companheira intervenha em sua conduta relacionada ao álcool ${ }^{(23)}$.

Atualmente não há um consenso sobre as causas da violência nem os motivos que levam os homens a cometeram as agressões contra as mulheres. No entanto, o conhecimento do perfil do agressor é uma ferramenta útil para prevenção de desigualdade de gênero e, em situações da violência, na identificação de grupos de risco, além de colaborar com a incorporação de medidas protetoras nas regiões mais vulneráveis, otimizando recursos e aplicação de programas e implantação da rede de serviços para as mulheres vítimas da violência ${ }^{(16,26)}$.

Portanto, com base na compreensão dos resultados apresentados, o alcance de dados confiáveis sobre as dimensões do perfil do agressor contribui para a análise do problema da violência contra as mulheres. Reconhece-se que a visibilidade de algumas informações no momento da notificação da violência permitiriam melhores correlações dos resultados e maior riqueza de detalhes acerca do fenômeno. Estes empecilhos não prejudicaram a reflexão sobre a temática, e sim acenderam o desafio para novas análises e futuros estudos.

\section{- CONCLUSÃO}

Houve associação entre a violência contra as mulheres com o tipo de relação afetiva, idade, estado civil, renda e uso abusivo de álcool. O perfil do agressor caracterizou-se por ser homem jovem que vive em união estável (marido/companheiro) com a vítima e que possui renda própria.

A violência de gênero mostrou-se ser um evento frequente na vida dessas mulheres vivenciado por um ciclo vicioso entre os casais com maior tempo de relacionamento, sendo o parceiro/companheiro íntimo apontado como principal agressor. Destacaram-se as violências física e psicológica entre os tipos mais prevalentes desse estudo.

O uso de álcool foi frequentemente associado aos atos violentos. Tal fato reforça a necessidade de políticas públicas, inerentes ao controle desse exacerbado consumo, que promovam mudança de comportamentos e ambientes saudáveis, por meio da educação em saúde que possam favorecer melhores estilos de vida na comunidade.

Diante do exposto, percebe-se que é imprescindível compreender o perfil do agressor e dos fatores associados à violência, para que profissionais de saúde e a sociedade em geral possam desenvolver medidas fundamentadas e interventivas para a prevenção, promoção da saúde e assistência das mulheres, aprimorando a rede de cuidados e de atendimento das vítimas em situação de violência.

\section{- REFERÊNCIAS}

1. Guedes RN, Silva ATMC, Fonseca RMGS. A violência de gênero e o processo saúde-doença das mulheres. Esc. Anna Nery. [Internet] 2009; 13(3) [acesso em 2 fev 2013]. Disponível: http://dx.doi.org/10.1590/S141481452009000300024.

2. Albuquerque JBC, César ESR, Silva VCL, Espínola LL, Azevedo EB, Ferreira Filha MO. Violência doméstica: características sociodemográficas de mulheres cadastradas em uma Unidade de Saúde da Família. Rev. Eletr. Enf. [Internet] 2013; 15(2). [acesso em 2 abr 2013]. Disponível: http://dx.doi.org/10.5216/ree.v15i2.18941.

3. Brasil. Lei n. 11.340, de 07 de agosto de 2006. Cria mecanismos para coibir a violência doméstica e familiar contra a mulher, nos termos do § 80 do art. 226 da Constituição Federal, da Convenção sobre a Eliminação de Todas as Formas de Discriminação contra as Mulheres e da Convenção Interamericana para Prevenir, Punir e Erradicar a Violência contra a Mulher; dispõe sobre a criação dos Juizados de Violência Doméstica e Familiar contra a Mulher; altera o Código de Processo Penal, o Código Penal e a Lei de Execução Penal; e dá outras providências. Diário Oficial da República Federativa do Brasil, Brasília, 07 ago. 2006.

4. Ribeiro DKL, Duarte JM, Lino KC, Fonseca MRCC. Caracterização das mulheres que sofrem violência doméstica na cidade de São Paulo. Saúde Colet. [Internet] 2009; 6(35). [acesso em 2 fev 2013]. Disponível: http://www. redalyc.org/articulo.oa?id=84212201003. 
5. Rocha SV, Almeida MMG, Araújo TM. Violência contra a mulher entre residentes de áreas urbanas de Feira de Santana, Bahia. Trends Psychiatry Psychother. [Internet] 2011; 33(3) [acesso em 2 fev 2013]. Disponível: http:// dx.doi.org/10.1590/S2237-60892011000300006.

6. Schraiber LB, D'Oliveira AFPL, Couto MT, Hanada H, Kiss LB, Durand JG, et al. Violência contra mulheres entre usuárias de serviços públicos de saúde da grande São Paulo. Rev. Saúde Pública. [Internet] 2007; 41(3) [acesso em 2 fev 2013]. Disponível: http://dx.doi.org/10.1590/S0034-89102007000300006.

7. Moura LBA, Gandolfi L, Vasconcelos AMN, Pratesi R. Violências contra mulheres por parceiro íntimo em área urbana economicamente vulnerável, Brasília, DF. Rev. Saúde Pública. [Internet] 2009; 43(6) [acesso em 2 fev 2013]. Disponível: http://dx.doi.org/10.1590/S0034-89102009005000069.

8. Rangel CMFRBA, Oliveira EL. Violência contra as mulheres: fatores precipitantes e perfil de vítimas e agressores. Fazendo Gênero 9 - Diásporas, diversidades, deslocamentos - UFSC. [Internet] 2010 [acesso em 2 fev 2013 ]. Disponível: http://www.fazendogenero.ufsc.br/9/resources/anais/1277848018_ARQUIVO_fazendogenero_ Celina_Elzira.pdf.

9. Gomes NP, Diniz NMF, Camargo CL, Silva MP. Homens e mulheres em vivência de violência conjugal: características socioeconômicas. Rev. Gaúcha Enferm. [Internet] 2012; 33(2) [acesso em 2 abr 2013]. Disponível: http://dx.doi.org/10.1590/S1983-14472012000200016.

10. Leite FMC, Moura MAV, Penna LHG. Percepções das mulheres sobre a violência contra a mulher: uma revisão integrativa da literatura. Av.enferm. [Internet] 2013; 31(2) [acesso em 20 mar 2015]. Disponível: http://www.scielo. org.co/pdf/aven/v31n2/v31n2a14.pdf.

11. Waiselfisz JJ. Mapa da Violência 2012. Atualização: Homicídio de mulheres no Brasil. [Internet] Brasil; 2012 [acesso em 15 jul 2013]. Disponível: http://mapadaviolencia.org.br/pdf2012/MapaViolencia2012_atual_mulheres. pdf.

12. Pazo CG, Aguiar AC. Sentidos da violência conjugal: análise do banco de dados de um serviço telefônico anônimo. Physis. [Internet] 2012; 22(1). [acesso em 25 mar 2013]. Disponível: http://dx.doi.org/10.1590/S010373312012000100014.

13. Leôncio KL, Baldo PL, João VM, Biffi RG. O perfil de mulheres vitimizadas e de seus agressores. Rev. enferm. UERJ. [Internet] 2008;16(3) [acesso em 25 mar 2013]. Disponível: http://www.facenf.uerj.br/v16n3/v16n3a02.pdf.

14. Osis MJD, Duarte GA, Faúndes A. Violência entre usuárias de unidades de saúde: prevalência, perspectiva e conduta de gestores e profissionais. Rev. Saúde Pública. [Internet] 2012; 46(2) [acesso em 22 nov 2012]. Disponível: http://dx.doi.org/10.1590/S0034-89102012005000019.

15. Madureira AB, Raimondo ML, Ferraz MIR, Marcovicz GV, Labronici LM, Mantovani MF. Esc. Anna Nery. [Internet] 2014;18(4) [acesso em 10 mar 2015]. Perfil de homens autores de violência contra mulheres detidos em flagrante: contribuições para o enfrentamento. Disponível: http://dx.doi.org/10.5935/1414-8145.20140085.

16. Camacho-Valadez D, Pérez-García M. El perfil demográfico/antropométrico del agresor denunciado de violencia de género al norte de México: estúdio descriptivo. Cuad. med. forense. [Internet] 2013; 19(1-2) [acesso em 20 mar 2015]. Disponível: http://dx.doi.org/10.4321/S1135-76062013000100005.

17. National Center for Injury Prevention and Control (USA). Understanding Intimate Partner Violence. [Internet] 2012 [acesso em 17 dez 2011]. Disponível: http://www.cdc.gov/violenceprevention/pdf/ipv-factsheet.pdf.

18. Rodriguez-Borrego MA, Vaquero-Abellan M, Rosa LB. Estudo transversal sobre fatores de risco de violência por parceiro íntimo entre enfermeiras. Rev. Latino-Am. Enfermagem. [Internet] 2012; 20(1) [acesso em 25 abr 2013]. Disponível: http://dx.doi.org/10.1590/S0104-11692012000100003.

19. Leite FMC, Bravim LR, Lima EFA, Primo CC. Violência contra a mulher: caracterizando a vítima, a agressão e o autor. J. res.: fundam. care. online. [Internet] 2015; 7(1) [acesso em 20 out 2015]. Disponível: https://dx.doi. org/10.9789/2175-5361.2015.v7i1.2181-2191.

20. Rasoulian M, Habib S, Bolhari J, Shooshtari MH, Nojomi M, Abedi Sh. Risk factors of domestic violence in Iran. J Environ Public Health. [Internet] 2014; 2014 [acesso em 27 mar 2015]. Disponível: http://dx.doi. org/10.1155/2014/352346. 
21. Schraiber LB, D'Oliveira AFPL, França-Junior I, Diniz S, Portella AP, Ludermir AB, et al. Prevalência da violência contra a mulher por parceiro íntimo em regiões do Brasil. Rev. Saúde Pública. [Internet] 2007; 41(5) [acesso em 25 abr 2013]. Disponível: http://dx.doi.org/10.1590/S0034-89102007000500014.

22. Presidência da República (BR). Secretaria de Políticas para as Mulheres. Plano Nacional de Políticas para as Mulheres. Brasília: Secretaria de Políticas para as Mulheres; 2013. [acesso em 15 set 2013]. Disponível: http:// www.mulheres.ba.gov.br/arquivos/File/Publicacoes/PlanoNacionaldePoliticasparaasMulheres20132015.pdf.

23. Deeke LP, Boing AF, Oliveira WF, Coelho EBS. A dinâmica da violência doméstica: uma análise a partir dos discursos da mulher agredida e de seu parceiro. Saúde Soc. [Internet] 2009; 18(2) [acesso em 2 fev 2013]. Disponível: http://dx.doi.org/10.1590/S0104-12902009000200008.

24. Rodríguez-Borrego MA, Abellán MV, Bertagnolli L, Muñoz-Gomariz E, Redondo-Pedraza R, Muñoz-Alonso A. Violencia del compañero íntimo: estúdio com profesionales de enfermería. Aten Primaria. [Internet] 2011; 43(8) [acesso em 20 mar 2015]. Disponível: https://dx.doi.org/10.1016/j.aprim.2010.07.009.

25. Costa AM, Moreira KAP, Henriques ACPT, Marques JF, Fernandes AFC. Violência contra a mulher: caracterização de casos atendidos em um centro estadual de referência. Rev. Rene. [Internet] 2011; 12(3) [acesso em 15 mar 2007]. Disponível: http://www.revistarene.ufc.br/revista/index.php/revista/article/view/274/pdf.

26. Capella MET, Martin-Fumadó C, Castro AMT, Capella RT, Martí XB, Rebollo-Soria MC. Estudio descriptivo de la violencia de género: análisis de 404 casos. Rev. Esp. Med. Legal. [Internet] 2013; 39(1) [acesso em 20 mar 2015]. Disponível: https://dx.doi.org/10.1016/j.reml.2012.08.003.

27. Zaleski M, Pinsky I, Laranjeira R, Ramisetty-Mikler S, Caetano R. Violência entre parceiros íntimos e consumo de álcool. Rev. Saúde Pública. [Internet] 2010; 44(1) [acesso em 15 mar 2007]. Disponível: http://dx.doi.org/10.1590/ S0034-89102010000100006.

28. Vieira EM, Perdona GCS, Almeida AM, Nakano AMS, Santos MA, Daltoso D, et al. Conhecimento e atitudes dos profissionais de saúde em relação à violência de gênero. Rev. bras. epidemiol. [Internet] 2009; 12(4) [acesso em 15 mar 2007]. Disponível: http://dx.doi.org/10.1590/S1415-790X2009000400007.

29. Silva CD, Gomes VLO, Acosta DF, Barlem ELD, Fonseca AD. Epidemiologia da violência contra a mulher: características do agressor e do ato violento. Rev enferm UFPE on line. [Internet] 2013; 7(1) [acesso em 15 mar 2013]. Disponível: http://www.revista.ufpe.br/revistaenfermagem/index.php/revista/article/download/3554/5157.

30. Mendes EV. O cuidado das condições crônicas na atenção primária à saúde: o imperativo da consolidação da estratégia da saúde da família. Brasília: Organização Pan-Americana da Saúde; 2012. 